THURSDAY, DECEMBER 19, 1889.

\section{THE EPIDEMIC OF INFLUENZA.}

$\mathrm{F}^{\mathrm{a}}$

$\mathrm{R}$ the first time after an immunity of nearly half

a century, our country is again threatened with an epidemic of influenza. The accounts we receive of epidemic illness in Russia, in Germany, and last of all in Paris, seem to make its irruption here every week more imminent. The question will, however, naturally be asked by the public, whether there is any real ground, in the history and in what is known of the nature of the disease, for such an apprehension? Is it a disease really brought from a distance? Is it anything more than the general prevalence of catarrhal affections, of colds and coughs, which the time of year, and the remarkably unsettled weather we have lately experienced, make readily explicable without any foreign importation? Indeed, is influenza, after all, anything more than a severe form of the fashionable complaint of the season?

To answer the last question first, and so to put it by, there can be little doubt that influenza is a distinct, specific affection, and not a mere modification of the common cold. The grounds for this belief cannot be fully stated here, but may be gathered by reference to the descriptions of the disease as seen in former outbreaks by physicians of the older generation ; for instance, by Sir Thomas Watson in his classical "Principles of Physic," or the late Dr. Peacock in his article in Quain's "Dictionary of Medicine."

These symptoms, the history of the disease, and its distribution, all justify us in treating it as a distinct and specific disease, which when it is prevalent will rarely be mistaken, though, with regard to isolated and sporadic cases, difficulties of diagnosis may arise. About its nature, or its affinities with other diseases, it is unnecessary to speculate. It will be sufficient to inquire what its recorded history in the past justifies us in expecting as to its behaviour in the future. There are few cases in which history proves so important an element in the scientific conception of a disease as it does in that of influenza. For hardly any disease shows a more marked tendency to occur in epidemics-that is, in outbreaks strictly limited in point of time. After long intervals of inaction or apparent death, it springs up again. Its chronology is very remarkable. Though probably occurring in Europe from very early times, it first emerged as a definitely known historical epidemic in the year 1510. Since then, more than 100 general European epidemics have been recorded, besides nearly as many more limited to certain localities. Many of them have in their origin and progress exhibited the type to which that of the present year seems to conform. We need not go further back than the great epidemic of 1782 , first traceable in Russia, though there believed to have been derived from Asia. In St. Petersburg, on January 2, coincidently with a remarkable rise of temperature from $35^{\circ} \mathrm{F}$. below freezing to $5^{\circ}$ above, 40,000 persons are said to have been simultaneously taken ill. Thence the disease spread over the Continent, where one-half of the inhabitants were supposed to have been affected, and reached England in VoL. XLI.-No. IO5I.
May. It was a remarkable feature in this epidemic that two fleets which left Portsmouth about the same time were attacked by influenza at sea about the same day, though they had no communication with each other or with the shore.

There were many epidemics in the first half of this century ; and the most important of them showed a similar course and geographical distribution. In 1830 started a formidable epidemic, the origin of which is referred to China, but which at all events by the end of the year had invaded Russia, and broke out in Petersburg in January 183r. Germany and France were overrun in the spring, and by June it had reached England. Again, two years later, in January 1833 , there was an outbreak in Russia, which spread to Germany and France successively, and on April 3, the first cases of influenza were seen in our metropolis; "all London," in Watson's words, "being smitten with it on that and the following day." On this same fateful day Watson records that a ship approaching the Devonshire coast was suddenly smitten with influenza, and within half an hour forty men were ill. In 1836 another epidemic appeared in Russia; and in January 1837 , Berlin and London were almost simultaneously attacked. Ten years later, in 1847 , the last great epidemic raged in our own country, and was very severe in November, having been observed in Petersburg in March, and having prevailed very generally all over Europe.

Some of these epidemics are believed to have travelled still further westward, to America; but the evidence on this point seems less conclusive. Without entering on further historical details, and without speculating on the nature of the disease, we may conclude that these broad facts are enough to show that a more or less rapid extension from east to west has been the rule in most of the great European epidemics of influenza; and that therefore its successive appearance in Russia, Germany, and France, makes its extension to our own country in the highest degree probable.

There are, it is true, certain facts on the other side, but they appear much less cogent. Since our last great visitation, certain epidemics of influenza have been recorded on the Continent which have not reached our shores. One was that of Paris in 1866-67; another at Berlin in 1874-75, of a disease described by the German doctors as influenza, and of great severity, affecting all classes of society. But in all epidemic and even contagious diseases there are outbreaks which seem to be self-linited from the first, showing no tendency to spread. This has been notably the case with plague and cholera. On the other hand, when an epidemic shows an expansive and progressive character, it is impossible to predict the extent to which it may spread. And the present epidemic, it must be confessed, appears to have this expansive character.

Many interesting points are suggested by this historical retrospect. What is the meaning of the westward spread of influenza, of cholera, and other diseases? Is it a universal law? To this it must be said, that it is by no means the universal law even with influenza, which has spread through other parts of the world in every kind of direction, but it does seem to hold good for Europe, at least in the northern parts. The significance of this law, 
as of the intermittent appearances of influenza, probably is that this is in Europe not an indigenous disease, but one imported from Asia. Possibly we may some day track it to its original home in the East, as the old plague and the modern cholera have been traced.

As regards, however, the European distribution of influenza, it has often been thought to depend upon the prevalence of easterly and north-easterly winds. There are many reasons for thinking that the contagium of this disease is borne through the air by winds rather than by human intercourse. One reason for thinking so is that it does not appear to travel along the lines of human communications, and, as is seen in the infection of ships at sea, is capable of making considerable leaps. The mode of transmission, too, would explain the remarkable facts noticed above of the sudden outbreak of the disease in certain places, and its attacking so many people simultaneously, which could hardly be the case if the infection had to be transmitted from one person to another.

Another important question, and one certain to be often asked, is suggested by the last-namely, whether influenza is conta gious. During former epidemics great care was taken to collect the experience of the profession on this point, and its difficulty is shown by the fact that opinions were much divided. Some thought the disease could be transmitted by direct contagion, while others doubted it. But there was and is a general agreement that this is not the chief way in which the disease spreads, either in a single town, or from place to place.

We must avoid the fascinating topic of the cause of influenza, or our limits would be speedily outrun. But one simple lesson may be drawn from the facts already mentioned-namely, that the disease is not produced by any kind of weather, though that, of all possible causes of disease, is the one most often incriminated in this country. It is true that some of our worst epidemics have occurred in winter, but several have happened in summer ; and the disease has been known in all parts of the world, in every variety of climate and atmospheric condition; so that it is certainly not due to a little more or less of heat or cold, moisture or dryness. Its constancy of type, the mode of its transmission, its independence of climatic and seasonal conditions, all suggest that its cause is "specific,"-that is, having the properties of growth and multiplication which belong to a living thing.

Whether the disease affects the lower animals is not absolutely certain, but the human epidemic has often been preceded or accompanied by an epidemic among horses of a very similar disease. It is pretty well known that such a disease is now very prevalent among horses in London. Nearly three weeks ago, one of the railway companies in London had 120 horses on the sick list, and the epidemic is still by no means extinguished. To a certain extent this must be taken as prognostic of human influenza.

It may be asked, if the influenza is really to come, can we form any notion how soon it is likely to appear? On such a point little beyond speculation is possible, for the rate at which the disease travels is extremely variable. Generally, it has taken some weeks, or even months, to traverse Europe, but occasionally much less, as, for instance, in 1833 , when it appeared to travel from Berlin to Paris in two days. It is now barely a month since the epidemic became noticeable in Petersburg, where, according to a correspondent of the British Medical Journal, it began on November I 5 or 17 , though sporadic cases had undoubtedly occurred earlier. In the beginning of December it was already widely spread throughout Russsia, and, as it would seem from the published accounts, must have been in Berlin about the same time. In Paris the first admitted and recorded cases occurred about December 10, though doubtless there were cases before that date. Both public and private accounts report it exceedingly prevalent there now. In London, notwithstanding the abundance of colds and coughs, and the mysterious rumours which have been afloat, it appears to the present writer doubtful whether any cases of true influenza have yet occurred. But according to its apparent rate of progress, it might, if coming from Paris, have already arrived here ; and it may be breaking out even while these lines are going through the press. But, on the whole, one would be disposed to give the epidemic another week or two. If its distribution depends, as it seems to do, on the winds, it is impossible to prophesy with much plausibility. A steady breeze setting in from one of the affected places might bring us an invasion in a very short time; but the current of air would have to be continuous over the whole district. Light local winds, whatever their direction, would, if the hypothesis be correct, have little effect. On the other hand, a steady frost, with an " anticyclone" period, might effectually keep off the disease. If, then, there is anything in the views above stated, prophecy belongs rather to the province of the weather-doctors than of the medical doctors.

Should the prospect seem a grave one, it may be some consolation to remember that an epidemic of influenza rarely lasts more than a few weeks-three to six-in one place; that it is rarely a fatal disease, though affecting large numbers of people; and that the present epidemic seems to have displayed on the Continent a decidedly mild type, which, according to the general rule, it is likely to retain.

J. F. P.

\section{THE HORNY SPONGES}

A Monograph of the Horny Sponges. By Robert von Lendenfeld. (London: Published for the Royal Society by Trübner and Co., Ludgate Hill, I889.)

WITHIN the last few years, and as a direct result of the famous Expedition of the Challenger, three most important monographs of the sponges belonging to the groups of the Hexactinellida, Monaxonida, and the Tetractinellida have been published, nor must the valuable contributions by Poléjaeff to the history of the remaining groups, Calcarea and Keratosa, be overlooked. The Calcarea had the advantage of having been already monographed by Haeckel, and so there only remained the Horny Sponges to be fully described, in order that the natural history of the sponges should be up to date.

Such a work has now been accomplished-thanks to the liberality of the Royal Society--by the labour and scientific skill of Dr. Robert von Lendenfeld. This monograph forms a fine quarto volume of over 900 pages, with an atlas of fifty lithographed plates.

While a student at the University of Graz, Lendenfeld 